\title{
Nanoporous Materials and Their Applications
}

\author{
Sibele B. C. Pergher ${ }^{1, *}$ and Enrique Rodríguez-Castellón ${ }^{2}$ (B) \\ 1 Departamento de Química, Universidade Federal do Rio Grande do Norte, Natal Caixa postal 1524, Brazil \\ 2 Department of Inorganic Chemistry, Faculty of Science, University of Malaga, 29071 Malaga, Spain; \\ castellon@uma.es \\ * Correspondence: sibelepergher@gmail.com; Tel.: +55-84-9941-35418
}

Received: 12 March 2019; Accepted: 18 March 2019; Published: 29 March 2019

Investigations into nanoporous materials and their applications continue to afford a wealth of novel materials and new applications. In fact, the ongoing quest for nanoporous materials with novel properties has led to many new materials and new applications for known materials.

This Special Issue is associated with the most recent advances in nanoporous material synthesis, as well as its applications.

The 12 articles comprising this Special Issue can be considered a representative selection of the current research on this topic, reflecting the diversity of nanoporous materials and their applications.

For example, Schwanke and Pergher [1] provide a review of nanoporous materials with MWW topology. They cover aspects of the synthesis of the MWW precursor and the tridimensional zeolite MCM-22, as well as their physicochemical properties, such as the Si/Al molar ratio, acidity, and morphology. In addition, this paper discusses the use of directing agents (SDAs) to obtain the different MWW-type materials reported thus far. The traditional post-synthesis modifications to obtain MWW-type materials with hierarchical architectures, such as expanded, swelling, pillaring, and delaminating structures, are shown together with recent routes to obtain materials with more open structures. New routes for the direct synthesis of MWW-type materials with a hierarchical pore architecture are also covered.

Silva et al. [2] study hierarchical materials by a method of opening mesopores in a microporous zeolite structure. They created mesopores in the Ultrastable USY zeolite $(\mathrm{Si} / \mathrm{Al}=15)$ using alkaline treatment $(\mathrm{NaOH})$ in the presence of cetyltrimethylammonium bromide surfactant, followed by hydrothermal treatment. The effects of the different concentrations of $\mathrm{NaOH}$ and the surfactant on the textural, chemical, and morphological characteristics of the modified zeolites are evaluated.

Also in the area of zeolite synthesis, Vinaches et al. [3] propose an alternative method for the introduction of aluminum into the STW zeolitic framework. This zeolite was synthesized in a pure silica form, and an aluminum source was added by in situ generated seeds. Characterization techniques, such as XRD and MAS NMR of 29Si and 27Al, were used to conclude that the aluminum was effectively introduced into the framework. The materials were tested as catalysts on the dehydration of ethanol, and they proved be selective to ethylene and diethyl ether, confirming the presence of acidic sites.

Another approach was analyzed by the group of Pereira et al. [4], who study the synthesis of zeolites from two metakaolins, one derived from the white kaolin and the other derived from the red kaolin, found in a deposit in the city of São Simão (Brazil). The A zeolite obtained was applied as an adsorbent to remove methylene blue, safranine, and malachite green from aqueous solutions.

Another applications approach was proposed by Zhang et al. [5], who compared two glycerol/ ZSM- 5 zeolite systems with different amount of residual gas by performing a series of experiments.

Besides zeolite materials, there exists one kind of micro and mesoporos materials built by pillarization of lamellar materials. On this subject, the paper of Jalil et al. [6] is very interesting. Jalil et al. synthesized, characterized, and evaluated three silica pillared clays as possible adsorbents of ciprofloxacin (CPX) and tetracycline (TC) from alkaline aqueous media. 
Another natural raw material was used in the separations process. Autie-Pérez et al. [7] study a raw porous volcanic glass from $\mathrm{Cuba}$ as an adsorbent for $\mathrm{Cu}^{2+}$ removal from dyes after activation with an acid solution. After $\mathrm{Cu}^{2+}$ adsorption, its capacity to separate n-paraffins from a mixture by inverse gas chromatography (IGC) was also evaluated. They showed that natural volcanic glass can be used in both heavy metal removal and paraffin separation for industrial purposes.

Mesoporous materials are very interesting because of their great accessibility to bulk molecules. On this subject, we have the study of Fernandes et al. [8], which analyzes the influence of Synthesis Parameters in Obtaining KIT-6 Mesoporous Materials, and the study of Busatta et al. [9], which examines the ethylene oligomerization reactions catalyzed by nickel- $\beta$-diimine complexes immobilized on $\beta$-zeolite, [Si]-MCM-41 and [Si,Al]-MCM-41, modified with an ionic liquid. They showed different selectivities depending on whether the material used zeolite (microporous) or MCM41 (mesoporous) materials. Also on this subject, Padula et al. [10] synthesized Mesoporous Niobium Oxyhydroxide Catalysts for Cyclohexene Epoxidation Reactions. These mesoporous catalysts were synthesized from the precursor $\mathrm{NbCl} 5$ and surfactant $\mathrm{CTAB}$ (cetyltrimethylammonium bromide) using different synthesis routes, in order to obtain materials with different properties, which are capable of promoting the epoxidation of cyclohexene. Catalytic studies have shown that mild reaction conditions promote high conversion.

Another interesting type of porous material are the MOFs, or Metal Organic Frameworks. Fuentes-Fernandez et al. [11] study the confined porous environment of MOFs as a system for studying reaction mechanisms. As an example of an important reaction, they study the dissociation of water-which plays a critical role in biology, chemistry, and materials science-in MOFs and show how the knowledge of the structure in this confined environment allows for an unprecedented level of understanding and control. Their results show that precise control of reactions within nano-porous materials is possible, opening the way for advances in fields ranging from catalysis to electrochemistry and sensors. Wu et al. [12] present an experimental investigation into the third-order nonlinearity of conventional crystalline (c-Si) and porous (p-Si) silicon with a Z-scan technique at 800-nm and 2.4- $\mu \mathrm{m}$ wavelengths.

Finally, I wish to express my gratitude to all the authors for their contributions to this Special Issue. I would also like to thank the reviewers for their kind, essential advice and suggestions. The contributions of the editorial, as well as the publishing, staff at Applied Science to this Special Issue are also highly appreciated. I hope readers from different research fields will enjoy this Open Access Special Issue and find a basis for further work in the exciting field of nanoporous materials.

\section{References}

1. Schwanke, A.; Pergher, S. Lamellar MWW-Type Zeolites: Toward Elegant Nanoporous Materials. Appl. Sci. 2018, 8, 1636. [CrossRef]

2. Silva, J.F.; Ferracine, E.D.; Cardoso, D. Effects of Different Variables on the Formation of Mesopores in Y Zeolite by the Action of CTA+ Surfactant. Appl. Sci. 2018, 8, 1299. [CrossRef]

3. Vinaches, P.; Rojas, A.; De Alencar, A.E.V.; Rodríguez-Castellón, E.; Braga, T.P.; Pergher, S.B.C. Introduction of Al into the HPM-1 Framework by In Situ Generated Seeds as an Alternative Methodology. Appl. Sci. 2018, 8, 1634. [CrossRef]

4. Pereira, P.M.; Ferreira, B.F.; Oliveira, N.P.; Nassar, E.J.; Ciuffi, K.J.; Vicente, M.A.; Trujillano, R.; Rives, V.; Gil, A.; Korili, S.; et al. Synthesis of Zeolite A from Metakaolin and Its Application in the Adsorption of Cationic Dyes. Appl. Sci. 2018, 8, 608. [CrossRef]

5. Zhang, Y.; Luo, R.; Zhou, Q.; Chen, X.; Dou, Y. Effect of Degassing on the Stability and Reversibility of Glycerol/ZSM-5 Zeolite System. Appl. Sci. 2018, 8, 1065. [CrossRef]

6. Roca Jalil, M.E.; Toschi, F; Baschini, M.; Sapag, K. Silica Pillared Montmorillonites as Possible Adsorbents of Antibiotics from Water Media. Appl. Sci. 2018, 8, 1403. [CrossRef] 
7. Autie-Pérez, M.; Infantes-Molina, A.; Cecilia, J.A.; Labadie-Suárez, J.M.; Rodríguez-Castellón, E. Separation of Light Liquid Paraffin $\mathrm{C}_{5}-\mathrm{C}_{9}$ with Cuban Volcanic Glass Previously Used in Copper Elimination from Water Solutions. Appl. Sci. 2018, 8, 295. [CrossRef]

8. Fernandes, F.R.D.; Pinto, F.G.H.S.; Lima, E.L.F.; Souza, L.D.; Caldeira, V.P.S.; Santos, A.G.D. Influence of Synthesis Parameters in Obtaining KIT-6 Mesoporous Material. Appl. Sci. 2018, 8, 725. [CrossRef]

9. Busatta, C.A.; Mignoni, M.L.; De Souza, R.F.; Bernardo-Gusmão, K. Nickel Complexes Immobilized in Modified Ionic Liquids Anchored in Structured Materials for Ethylene Oligomerization. Appl. Sci. 2018, 8 , 717. [CrossRef]

10. Padula, I.D.; Chagas, P.; Furst, C.G.; Oliveira, L.C.A. Mesoporous Niobium Oxyhydroxide Catalysts for Cyclohexene Epoxidation Reactions. Appl. Sci. 2018, 8, 881. [CrossRef]

11. Fuentes-Fernandez, E.M.A.; Jensen, S.; Tan, K.; Zuluaga, S.; Wang, H.; Li, J.; Thonhauser, T.; Chabal, Y.J. Controlling Chemical Reactions in Confined Environments: Water Dissociation in MOF-74. Appl. Sci. 2018, 8, 270. [CrossRef]

12. Wu, R.; Collins, J.; Canham, L.T.; Kaplan, A. The Influence of Quantum Confinement on Third-Order Nonlinearities in Porous Silicon Thin Films. Appl. Sci. 2018, 8, 1810. [CrossRef]

(C) 2019 by the authors. Licensee MDPI, Basel, Switzerland. This article is an open access article distributed under the terms and conditions of the Creative Commons Attribution (CC BY) license (http:/ / creativecommons.org/licenses/by/4.0/). 